\title{
Prevalence of Intracranial Aneurysm in Patients with Aortopathy: A Systematic Review with Meta-Analyses
}

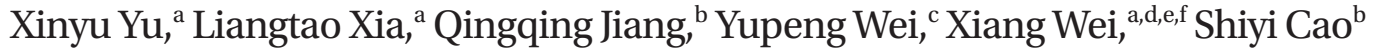 \\ ${ }^{a}$ Division of Cardiothoracic and Vascular Surgery, Tongji Hospital, Tongji Medical College, Huazhong University of Science and Technology, \\ Wuhan, China \\ ${ }^{\text {'S }}$ chool of Public Health, Tongji Medical College, Huazhong University of Science and Technology, Wuhan, China \\ 'Biological Science Department, University of Pittsburgh, Pittsburgh, PA, USA \\ ${ }^{d}$ Key Laboratory of Organ Transplantation, Ministry of Education, Tongji Hospital, Tongji Medical College, Huazhong University of Science and \\ Technology, Wuhan, China \\ eNHC Key Laboratory of Organ Transplantation, Wuhan, China \\ ${ }^{f}$ Key Laboratory of Organ Transplantation, Chinese Academy of Medical Sciences, Wuhan, China
}

Background and Purpose Patients with aortic disease might have an increased risk of intracranial aneurysm (IA). We conducted this research to assess the prevalence of IA in patients with aortopathy, considering the impact of gender, age, and cardiovascular risk factors.

Methods We searched PubMed and Scopus from inception to August 2019 for epidemiological studies reporting the prevalence of IA in patients with aortopathy. Random-effect meta-analyses were performed to calculate the overall prevalence, and the effect of risk factors on the prevalence was also evaluated. Anatomical location of IAs in patients suffered from distinct aortic disease was extracted and further analyzed.

Results Thirteen cross-sectional studies involving 4,041 participants were included in this systematic review. We reported an estimated prevalence of 12\% (95\% confidence interval [Cl], 9\% to $14 \%$ ) of IA in patients with aortopathy. The pooled prevalence of IA in patients with bicuspid aortic valve, coarctation of the aorta, aortic aneurysm, and aortic dissection was $8 \%(95 \% \mathrm{Cl}, 6 \%$ to $10 \%), 10 \%(95 \% \mathrm{Cl}, 7 \%$ to $14 \%), 12 \%(95 \% \mathrm{Cl}, 9 \%$ to $15 \%)$, and $23 \%(95 \% \mathrm{Cl}, 12 \%$ to $34 \%)$, respectively. Gender (female) and smoking are risk factors related to an increased risk of IA. The anatomical distribution of IAs was heterogeneously between participants with different aortic disease.

Conclusions According to current epidemiological evidence, the prevalence of IA in patients with aortic disease is quadrupled compared to that in the general population, which suggests that an early IA screening should be considered among patients with aortic disease for timely diagnosis and treatment of IA.
Correspondence: Shiyi Cao School of Public Health, Tongji Medical College, Huazhong University of Science and Technology, No. 13 Hangkong Road, Wuhan 430030, China Tel: +86-27-83693756

Fax: +86-27-83693756

E-mail: caoshiyi@hust.edu.cn

Co-correspondence: Xiang Wei Division of Cardiothoracic and Vascular Surgery, Tongji Hospital, Tongji Medical College, Huazhong University of Sci-

ence and Technology, No. 1095 Jiefang Avenue, Wuhan 430030, China

Tel: +86-27-83663394

Fax: +86-27-83663394

E-mail: xiangwei@tjh.tjmu.edu.cn

Received: May 22, 2019

Revised: September 21, 2019

Accepted: October 15, 2019

Keywords Intracranial aneurysm; Aortic diseases; Prevalence; Meta-analysis

Copyright $\odot 2020$ Korean Stroke Society

This is an Open Access article distributed under the terms of the Creative Commons Attribution Non-Commercial License (http://creativecommons.org/licenses/by-nc/4.0/) which permits unrestricted non-commercial use, distribution, and reproduction in any medium, provided the original work is properly cited. 


\section{Introduction}

The worldwide prevalence of intracranial aneurysm (IA) in the general population is around $3.2 \%$, and the rupture of IA causes subarachnoid hemorrhage, which is life-threatening and mostly attacks relatively young adults. ${ }^{1}$ Since most IAs are asymptomatic and concealed, identifying IAs remains arduous, however, indispensable. Due to the advancing availability and quality of brain imaging techniques (e.g., magnetic resonance imaging scanning), the early diagnosis of IA in adults is promising, ${ }^{2}$ especially in high-risk patients with selected conditions. ${ }^{3}$

The guidelines for unruptured IAs ${ }^{4}$ indicate a higher prevalence of IA in patients with bicuspid aortic valve (BAV) or coarctation of the aorta (CoA). A propositional screening is suggested among patients with either of the two diseases. Recent studies $^{3,5-8}$ propose that aortic aneurysm and aortic dissection are also involved with an increased risk of IA. BAV, CoA, aortic aneurysm, and aortic dissection are four aortic diseases which attack aortic valve or segmentation of the aorta with distinct pathological manifestations. Aortic disease and IA are vascular disorders which share similar pathophysiologic mechanism, however, in the disparate area of the cardiovascular system. Both genetic factors and excessive hemodynamic stress caused by hypertension may play an essential role in the pathogenesis of the two diseases. ${ }^{3}$ According to previous epidemiological studies, $^{3,5-13}$ the disease status of aortopathy might be used to predict the presence of IA.

The relation between IA and aortopathy was revealing, and the prevalence of IA in patients with aortopathy could direct population screening of IA. However, no review had systematically summarized this material. In the present systematic review, our primary goal was to report on an estimated prevalence of IA in patients struggled with aortopathy or different aortic disease (BAV, CoA, aortic aneurysm, and aortic dissection). We wanted to find whether age, gender, and cardiovascular risk factors affect the overall prevalence. Additionally, the anatomical distribution of IAs between different groups of aortic disease was analyzed in this research. The secondary aim was to discuss the presence of aortic disease in patients suffered from IA.

\section{Methods}

\section{Search strategy}

Results of this systematic review and meta-analysis were reported according to Preferred Reporting Items for Systematic Reviews and Meta-Analyses (PRISMA) 2009 guidelines (Supplementary Material). ${ }^{14}$ We systematically searched PubMed and Scopus to identify studies on the prevalence of IA in pa- tients with aortopathy or the presence of aortic disease in people who suffered from IAs published before August 2019. A combination of keywords was used to grab eligible studies: aorta, aortic dissection, aortic aneurysm, aortic dilatation, CoA, BAV aortopathy, and IA. Searching terms were listed in the Supplementary Material. We did not set any other limitation in this search strategy. References of included studies were manually checked to prevent the omission of eligible research.

\section{Study selection}

Two collaborators (X.Y. and L.X.) individually screened the studies from two databases for eligibility according to predefined selection criteria: cohort study, case-control study, and crosssectional study reported an accurate prevalence of IA in patients with aortic disease; indicated a prevalence of aortic disease in patients suffered from IA. In studies evaluating the prevalence of IA, study population should be patients with brain imaging to avoid the omission of cases. Titles and abstracts from database research were examined and ineligible studies were refused. Full texts of remaining publications were carefully reviewed subsequently. We excluded studies on a specific population (e.g., children). Disagreements were solved in a discussion with a senior author (S.C.).

\section{Data extraction}

Two investigators (X.Y. and L.X.) independently extracted data on authors, published year, study country, study design (cohort, case-control, or cross-sectional), event (IA or aortic aneurysm), diagnostic criteria (for IA and aortic diseases), number of events, number of participants from included articles. To investigate the effect of cardiovascular risk determinants on the overall prevalence, risk factors (e.g., gender, smoking) in each study were documented in details. We recorded age and the exact number of patients with or without dichotomous risk factor in two groups (patients with both aortopathy and IA; patients with aortopathy alone). In a previous study, ${ }_{1}^{8}$ a differing anatomical distribution pattern of IA between subgroups of the aortic aneurysm was reported, and we tended to find whether this site-specific phenomenon exists between different kinds of aortic disease. We extracted the accurate location and size of IAs provided by original work. If prevalence from reports were adjusted by confounding factors, we grabbed primary data to reduce the heterogeneity between studies. Multiple reports in a single article were analyzed separately. A consensus could be reached through group discussion. If the definite number of events/participants was not provided in eligible studies, we tried to contact authors for more information. 


\section{Definitions}

We included BAV, CoA, aortic aneurysm, and aortic dissection as aortopathy (aortic disease) in this literature. BAV was an inherited form of heart disease, but there remained a notable association between BAV and aorta, and we considered BAV an aortic disease in our research. To analyze the site-specific distribution pattern of IA in patients with different aortopathy, IAs were divided into three groups according to their anatomical locations: intracranial internal carotid artery (ICA), anterior choroidal artery, superior hypophyseal artery, and ophthalmic artery (ICA-IA); anterior circulation excluding the ICA, comprising anterior cerebral, anterior communicating, and middle cerebral arteries (anterior circulation-IA [Ant-IA]); and posterior circulation consisted of arteries not included in the ICA-IA or Ant-IA group (Post-IA). ${ }^{8}$ This classification for IAs was originally used by Shin et al. ${ }^{8}$

\section{Quality appraisal}

The methodological quality of included studies (cross-sectional studies) was evaluated using a modified Newcastle-Ottawa scale developed by Fralick et al. ${ }^{15}$ The modified scale covered three perspectives (participant selection; comparability; assessment of outcome) of methodology. Two investigators (X.Y. and L.X.) independently assessed the methodological quality. All results were reviewed by a third investigator (S.C.) with disagreements being resolved through consensus. We did not set any eligibility restrictions on the quality assessment score for the studies that fulfilled inclusion criteria.

\section{Statistical analysis}

Three studies reported a prevalence of aortic disease in IA population, and we qualitatively described the result on this issue. The main outcome was a pooled prevalence of IA in patients with aortopathy. The meta-analysis for overall prevalence was conducted in Stata version 14.0 (StataCorp., College Station, TX, USA) and forest plot was prepared in $\mathrm{R}$ version 3.6.1 using the forestplot packages (R Foundation for Statistical Computing, Vienna, Austria). Study heterogeneity was fully assessed by the $\mathrm{I}^{2}$ statistic (0\% to 100\%) describing the proportion of total variation. Little heterogeneity was defined as $I^{2}<25 \%$, moderate heterogeneity was $25 \%<I^{2}<50 \%$, and $I^{2}>50 \%$ stands for a substantial heterogeneity. We expected heterogeneity in the methodology of included studies, hence the meta-analysis was based on a random-effect model. We used the data of participants/events extracted from original articles to calculate prevalence and corresponding 95\% confidence interval (Cl). Metaanalysis was performed in predefined subgroups of aortopathy (BAV, CoA, aortic aneurysm, and aortic dissection). Publication bias was not detected for the limited number of studies in each subgroup. No sensitivity analysis was planned. We investigated risk factors that may influence the estimated prevalence of IA in patients suffered from aortopathy. All risk factors reported in at least three studies were included in pooled analyses using a random-effect model. Data of dichotomous risk factors were arranged in fourfold tables and odds ratios (ORs) were obtained through calculation. Continuous risk factors were raised as standardized mean differences by Stata version 14.0 and transformed to ORs according to the formula developed in the Cochrane handbook version 5.1.0. ${ }^{16}$ We calculated the OR of risk factors on the platform of IBM SPSS Statistics version 24 (IBM Co., Armonk, NY, USA). Primary ORs were pooled on the platform of Stata 14.0, and the final result was displayed in a forest plot produced by $\mathrm{R}$. Continuous variables were compared in analyses of variance or unpaired Student's t-test. All $P$-values were two tails, and $P$-values $<0.05$ were considered significant.

The present work is a systematic review with meta-analyses of published studies, and data were collected from published materials, and thus ethical approval was not necessary for this article.

\section{Data availability}

All extracted data could be made available upon request from qualified investigators to corresponding authors.

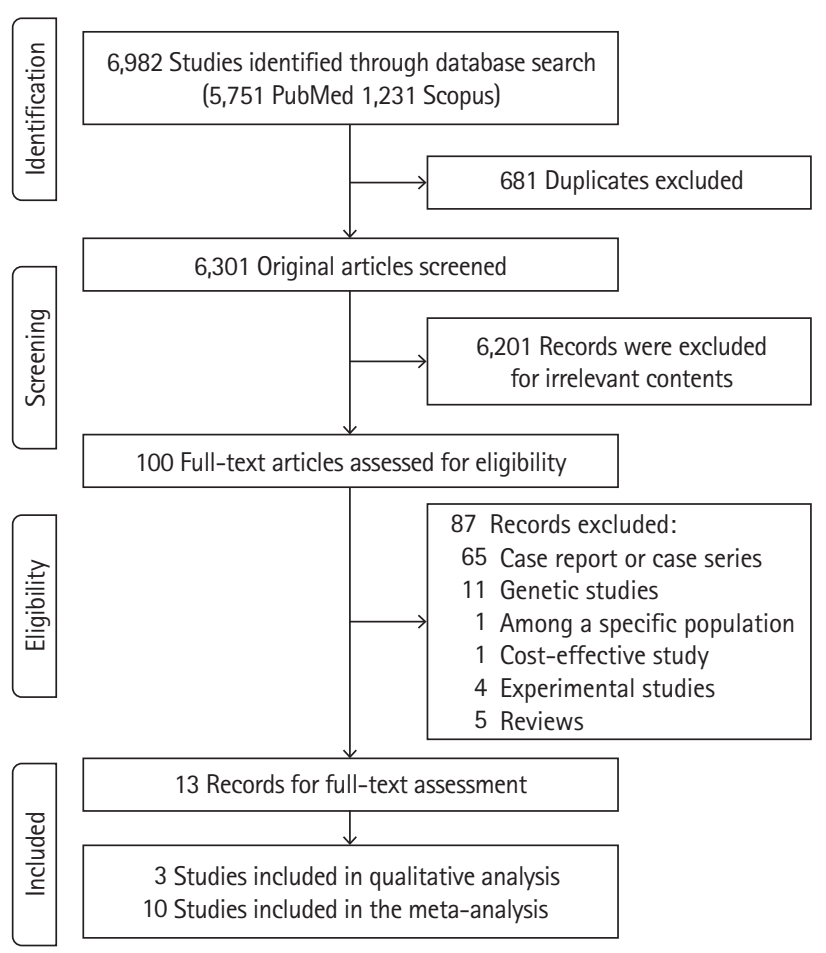

Figure 1. Study screening flow diagram. 


\section{Results}

\section{Literature search}

Figure 1 showed the flow diagram for search strategy and selection procedure of this systematic review. The primary database search yielded 6,982 articles. After removal of duplicates, 6,301 researches were identified and their titles/abstracts were manually retrieved for further evaluation. Of 100 studies considered for eligibility, 13 records were included in the full-text assessment. In the process of screening, one study was conducted in children (mean age 16) with $\mathrm{CoA}_{1}{ }^{17}$ and we excluded this article for the specific study population, and we also excluded a cohort study in which not all participants were patients with brain imaging. ${ }^{18}$ After an inter-observer agreement between reviewers for study inclusion, three studies considering the prevalence of aortic disease in patients with IA were included in qualitative analysis, and a total of ten studies were included in the meta-analysis which reported an estimated prevalence of IA among patients with aortopathy.

\section{Study characteristics}

Overall, 13 cross-sectional studies were included in this systematic review (Table 1). Three studies investigated the proportion of patients with aortic aneurysm or BAV in patients suffered from IA. ${ }^{19-21}$ Ten studies reported a prevalence of IA in patients with aortopathy: two studies were in patients with $\mathrm{BAV}_{i}^{10,13}$ three studies considered patients with $\mathrm{Co}_{i}^{9}, 9^{911,12}$ three studies were conducted in patients with aortic aneurysm; $;, 7,8$ one study investigated aortic dissection; ${ }^{3}$ and one study examined both aortic aneurysm and aortic dissection. ${ }^{6}$ Seven studies were from the USA, and three studies from South Korea. One study was from Japan, and one study from the UK, and one study from Finland. Of the total 4,041 participants, 1,261 patients were suffered from IA and 3,193 were patients struggled with the aortic disease. IAs were diagnosed by computed tomography angiography, magnetic resonance angiography (MRA) or digital subtraction angiography, and aortic diseases were identified by echocardiography, computed tomography, and MRA. Quality assessment of included studies was displayed in Supplementary Table 1, and overall study quality was moderate (6 to 7 points). We did not exclude any study on the basis of the quality assessment.

\section{Quantitative synthesis}

Meta-analysis for the prevalence of intracranial aneurysm in patients with different aortic disease

The meta-analysis of the overall prevalence comprised data of
3,132 patients with four kinds of aortopathy (Figure 2). Based on 10 studies, the pooled analysis reported an estimated prevalence of $12 \%\left(95 \% \mathrm{Cl}, 9 \%\right.$ to $\left.14 \% ; I^{2}=64.3 \%\right)$ of IA in patients with aortopathy. In the classification of aortic diseases, the pooled prevalence of IA was $8 \%\left(95 \% \mathrm{Cl}, 6 \%\right.$ to $10 \%$; $\left.I^{2}=0.0 \%\right)$ in patients with $\mathrm{BAV}, 10 \%\left(95 \% \mathrm{Cl}, 7 \%\right.$ to $\left.14 \% ; \mathrm{I}^{2}=0.0 \%\right)$ in participants with $\mathrm{CoA}, 12 \%\left(95 \% \mathrm{Cl}, 9 \%\right.$ to $\left.15 \% ; \mathrm{I}^{2}=62.7 \%\right)$ in patients suffered from aortic aneurysm, and $23 \%(95 \% \mathrm{Cl}$, $12 \%$ to $34 \% ; l^{2}=27.5 \%$ ) in patients who had a dissection of aorta.

\section{Risk factors}

Seven risk factors (Supplementary Figures 1-7) were reported in three or more studies: female gender, ${ }^{3,6,7,9-13}$ smoking, $^{3,6,7,10-13}$ hypertension, ${ }^{3,6,7,10-13}$ age, ${ }_{1}^{6,9,11,13}$ diabetes, ${ }^{3,6,7,13}$ hyperlipidemia, ${ }_{1}^{3,6,7}$ and the overlapping of two aortic diseases. ${ }^{7,9,11-13}$ Pooled analyses yielded effect estimates for the effect of risk factors on the increased prevalence of IAs (Figure 3). Female gender (pooled $\mathrm{OR}, 1.86 ; 95 \% \mathrm{Cl}, 1.33$ to 2.60 ) and smoking (pooled $\mathrm{OR}, 1.38$; $95 \% \mathrm{Cl}, 1.04$ to 1.83 ) were associated with an increased risk of IAs.

Site-specific relationships of intracranial aneurysm with different aortic disease

No significant difference was found in the mean size of IAs between subgroups of aortic disease $(P=0.217)$ (Table 2). However, the anatomical distribution of IAs was heterogeneous between patients with different aortic disorders (Table 2). The Ant-IAs distributed evenly among four groups ( 0.4 to 0.5 per person), but the distribution of ICA-IAs and Post-IAs were statistically different between patients with different aortic diseases $(P<0.001$ and $P=0.014)$. ICA-IAs were reported most frequently in patients with aortic aneurysm (0.6 per person), and least frequently in patients with $\mathrm{CoA}$ (0.1 per person). The frequency of Post-IAs was highest in the group with $\mathrm{CoA}$ (0.4 per person) and least in the group with BAV or aortic aneurysm (0.2 per person).

\section{Heterogeneity}

Heterogeneity obtained in the analyses for prevalence and risk factors was not obvious. The prevalence reported by Lee et al. ${ }^{6}$ was slightly higher, and this might be associated with a specific methodology of the study, which could induce a significant heterogeneity in the meta-analysis for overall prevalence. Since age was a continuous factor and the population was not strictly limited at included studies, the pooled analysis for age showed substantial heterogeneity $\left(I^{2}=88.3 \%\right)$. 


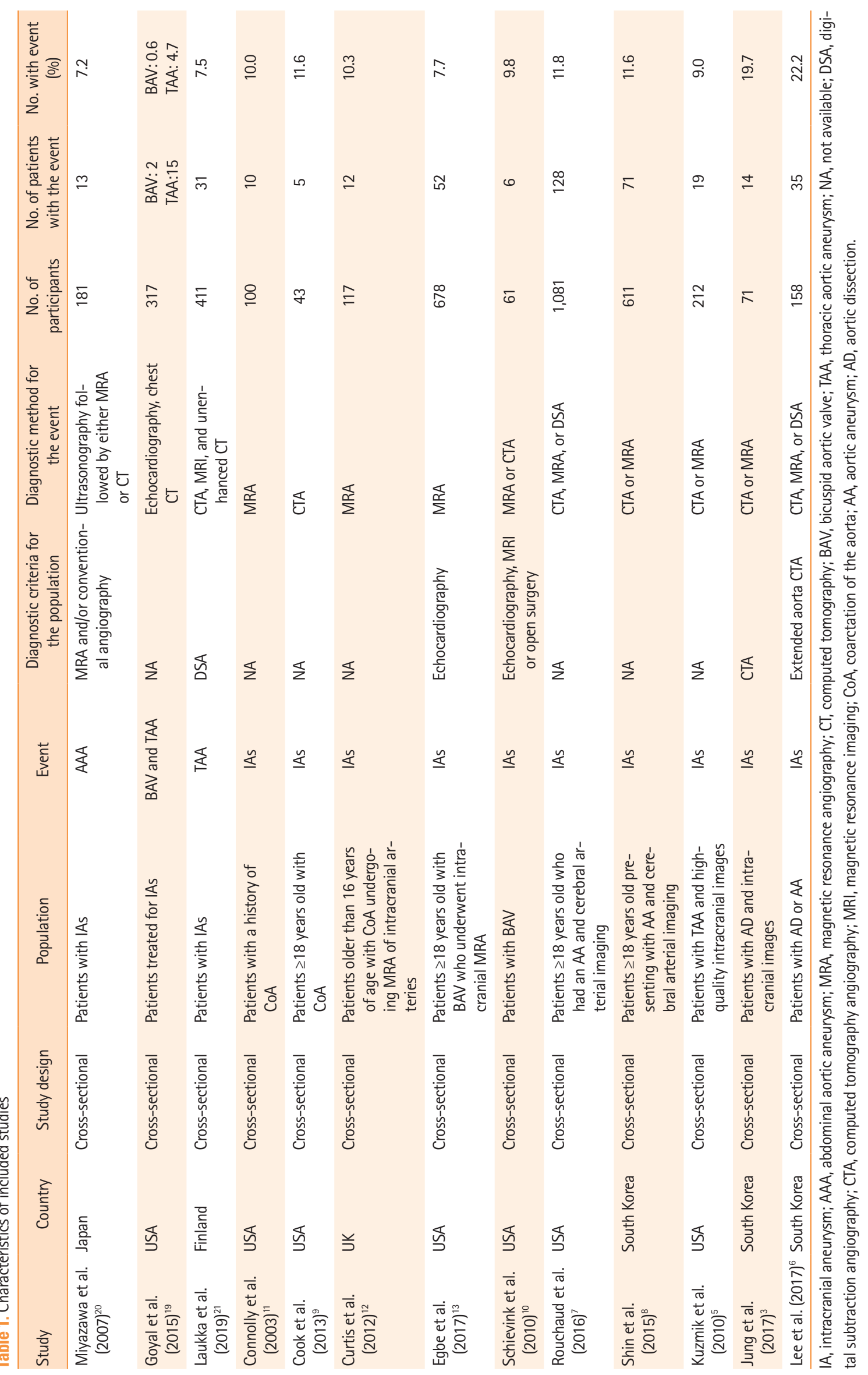




\begin{tabular}{|c|c|c|c|c|}
\hline \multirow{2}{*}{$\begin{array}{l}\text { Study } \\
\text { Bicuspid aortic valve }\end{array}$} & \multicolumn{2}{|c|}{ No. of patients } & \multirow[t]{2}{*}{ Prevalence } & \multirow[t]{2}{*}{ Weight (\%) } \\
\hline & & & & \\
\hline & 678 & $\rightarrow$ & $0.08(0.06,0.10)$ & 16.34 \\
\hline Schievink et al. $(2010)^{10}$ & 61 & $\longrightarrow$ & $0.10(0.02,0.17)$ & 6.07 \\
\hline I-squared $=0.0 \%, P=0.583$ & & $\diamond$ & $0.08(0.06,0.10)$ & 22.41 \\
\hline \multicolumn{5}{|l|}{ Coarctation of aorta } \\
\hline Curtis et al. (2012) ${ }^{12}$ & 117 & $\rightarrow-$ & $0.10(0.05,0.16)$ & 8.80 \\
\hline Connolly et al. (2003) & 100 & $\longrightarrow-$ & $0.10(0.04,0.16)$ & 8.18 \\
\hline Cook et al. $(2013)^{9}$ & 43 & $\longrightarrow$ & $0.12(0.02,0.21)$ & 4.22 \\
\hline I-squared $=0.0 \%, P=0.959$ & & $<$ & $0.10(0.07,0.14)$ & 21.21 \\
\hline \multicolumn{5}{|l|}{ Aortic aneurysm } \\
\hline Rouchaud et al. (2016) & 1,081 & $-\square$ & $0.12(0.10,0.14)$ & 16.50 \\
\hline Shin et al. $(2015)^{8}$ & 611 & $-\square$ & $0.12(0.09,0.14)$ & 15.13 \\
\hline Kuzmik et al. $(2010)^{5}$ & 212 & $-\square-$ & $0.09(0.05,0.13)$ & 12.09 \\
\hline Lee et al. $(2017)^{6}$ & 133 & $\longrightarrow$ & $0.20(0.13,0.27)$ & 6.82 \\
\hline I-squared $=62.7 \%, P=0.045$ & & $\diamond$ & $0.12(0.09,0.15)$ & 50.54 \\
\hline \multicolumn{5}{|l|}{ Aortic dissection } \\
\hline Jung et al. $(2017)^{3}$ & 71 & $\longrightarrow$ & $0.20(0.10,0.29)$ & 4.46 \\
\hline Lee et al. $(2017)^{6}$ & 25 & $\longrightarrow$ & $0.32(0.14,0.50)$ & 1.39 \\
\hline I-squared $=27.5 \%, P=0.240$ & & $\longrightarrow$ & $0.23(0.12,0.34)$ & 5.84 \\
\hline \multicolumn{5}{|l|}{ Overall } \\
\hline I-squared $=64.3 \%, P=0.002$ & 3,132 & $\infty$ & $0.12(0.09,0.14)$ & 100.00 \\
\hline
\end{tabular}

Figure 2. Meta-analysis for the prevalence of intracranial aneurysm in patients with aortopathy.

\begin{tabular}{|c|c|c|}
\hline Risk factor & No. of patients & Odds ratio \\
\hline $\begin{array}{l}\text { Female gender (9 studies) } \\
\text { I-squared }=15.7 \%, P=0.302\end{array}$ & 2,309 & $1.86(1.33,2.60)$ \\
\hline $\begin{array}{l}\text { Smoking (8 studies) } \\
\text { I-squared }=0.0 \%, P=0.564\end{array}$ & 2,266 & $1.38(1.04,1.83)$ \\
\hline $\begin{array}{l}\text { Hypertension (8 studies) } \\
\text { I-squared }=25.5 \%, P=0.225\end{array}$ & 2,266 & $1.49(0.99,2.25)$ \\
\hline $\begin{array}{l}\text { Two aortic diseases ( } 5 \text { studies) } \\
\text { I-squared }=53.7 \%, P=0.071\end{array}$ & 2,019 & $1.06(0.55,2.03)$ \\
\hline $\begin{array}{l}\text { Age ( } 5 \text { studies) } \\
\text { I-squared }=88.3 \%, P=0.000\end{array}$ & 979 & $1.72(0.47,6.36)$ \\
\hline $\begin{array}{l}\text { Diabetes ( } 3 \text { studies) } \\
\text { I-squared }=0.0 \%, P=0.970\end{array}$ & 1,892 一七 & $0.84(0.57,1.23)$ \\
\hline $\begin{array}{l}\text { Hyperlipidemia ( } 3 \text { studies) } \\
\text { I-squared }=0.0 \%, P=0.996\end{array}$ & $1,285 \longrightarrow$ & $0.82(0.56,1.19)$ \\
\hline
\end{tabular}

Figure 3. Risk factors for the presence of intracranial aneurysms in patients with aortic diseases.

\section{Qualitative synthesis}

Of three included studies, Goyal et al. ${ }^{19}$ indicated that the prevalence of BAV and thoracic aortic aneurysm in IA patients were $0.6 \%, 4.7 \%$ respectively. Miyazawa et al. ${ }^{20}$ reported a prevalence of $7.2 \%$ of abdominal aortic aneurysm in patients with IA. Laukka et al. ${ }^{21}$ showed a higher prevalence of thoracic aortic aneurysm (7.5\%) in IA patients compared to the general population. Three studies suggested several risk factors (e.g., age and smoking) for this association, but we could not further analyze these factors due to the limited data.

\section{Discussion}

Overall, this article suggests that around $12 \%$ of patients with 
Table 2. Location and size of intracranial aneurysm in populations with different aortic disease

\begin{tabular}{|c|c|c|c|c|c|c|c|c|}
\hline \multirow{2}{*}{ Variable } & \multirow{2}{*}{$\begin{array}{c}\text { Total }{ }^{*} \\
(\mathrm{n}=351)\end{array}$} & \multirow{2}{*}{$\begin{array}{c}\text { BAV } \\
(n=58)\end{array}$} & \multirow{2}{*}{$\begin{array}{c}\text { CoA } \\
(n=26)\end{array}$} & \multirow{2}{*}{$\begin{array}{c}A D \\
(n=22)\end{array}$} & \multicolumn{3}{|c|}{ AA } & \multirow{2}{*}{$P^{+}$} \\
\hline & & & & & Total $^{+}(n=245)$ & TAA $(n=88)$ & AAA $(n=87)$ & \\
\hline No. of studies & 10 & 2 & 3 & 2 & 4 & 4 & 3 & \\
\hline Size of IA (mm) & $5.43 \pm 5.01$ & $3.57 \pm 1.76$ & $3.78 \pm 1.62$ & $5.56 \pm 3.47$ & $5.68 \pm 5.43$ & $5.82 \pm 5.85$ & $5.4 \pm 4.4$ & 0.217 \\
\hline No. of IA & 431 (1.23) & $66(1.1)$ & $27(1.0)$ & $22(1.0)$ & 316 (1.3) & $113(1.3)$ & $110(1.3)$ & $<0.001$ \\
\hline \multicolumn{9}{|l|}{ Location of IA } \\
\hline Ant-IA & $163(0.5)$ & $26(0.4)$ & $13(0.5)$ & $10(0.5)$ & $114(0.5)$ & $47(0.5)$ & $34(0.4)$ & 0.978 \\
\hline ACA & 45 & 9 & 4 & 3 & 29 & 11 & 7 & \\
\hline ACoA & 35 & 6 & 2 & 0 & 27 & 15 & 9 & \\
\hline MCA & 93 & 11 & 7 & 7 & 58 & 21 & 18 & \\
\hline ICA-IA & $193(0.5)$ & $26(0.4)$ & $3(0.1)$ & $5(0.2)$ & $159(0.6)$ & $51(0.6)$ & $63(0.7)$ & $<0.001$ \\
\hline ICA & 179 & 15 & 3 & 5 & 156 & 51 & 61 & \\
\hline AChoA & 8 & 6 & 0 & 0 & 2 & 0 & 1 & \\
\hline SHA & 1 & 0 & 0 & 0 & 1 & 0 & 1 & \\
\hline $\mathrm{OA}$ & 5 & 5 & 0 & 0 & 0 & 0 & 0 & \\
\hline Post-IA & $75(0.2)$ & $14(0.2)$ & $11(0.4)$ & $7(0.3)$ & $43(0.2)$ & $15(0.2)$ & $13(0.1)$ & 0.014 \\
\hline PCoA & 7 & 2 & 3 & 0 & 2 & 1 & 0 & \\
\hline PCA & 16 & 7 & 2 & 0 & 7 & 4 & 1 & \\
\hline SCA & 7 & 4 & 2 & 0 & 1 & 0 & 0 & \\
\hline PICA & 9 & 1 & 1 & 0 & 7 & 2 & 1 & \\
\hline VA/BA & 36 & 0 & 3 & 7 & 26 & 8 & 11 & \\
\hline \multicolumn{9}{|l|}{ Proportions of IA } \\
\hline Ant-IA (\%) & 37.8 & 39.4 & 48.1 & 45.5 & 36.1 & 41.6 & 30.9 & \\
\hline ICA-IA (\%) & 44.8 & 39.4 & 11.1 & 22.7 & 50.3 & 45.1 & 57.3 & \\
\hline Post-IA (\%) & 17.4 & 21.2 & 40.8 & 31.8 & 13.6 & 13.3 & 11.8 & \\
\hline
\end{tabular}

Values are presented as mean \pm standard deviation or number (number of intracranial aneurysm per person).

$B A V$, bicuspid aortic valve; $C O A$, coarctation of the aorta; $A D$, aortic dissection; $A A$, aortic aneurysm; TAA, thoracic aortic aneurysm; $A A A$, abdominal aortic aneurysm; IA, intracranial aneurysm; Ant-IA, IA in anterior circulation arteries after bifurcation of the internal carotid artery; $A C A$, anterior cerebral artery; $A C o A$, anterior communicating artery; MCA, middle cerebral artery; ICA-IA, IA in internal carotid artery and branches except for Ant-IA; ICA, internal carotid artery; $A C h o A$, anterior choroidal artery; SHA, superior hypophyseal artery; OA, ophthalmic artery; Post-IA, IA in posterior circulation artery; PCoA, posterior communicating artery; PCA, posterior cerebral artery; SCA, superior cerebellar artery; PICA, posterior inferior communicating artery; VA, vertebral artery; BA, basilar artery. ${ }^{*} \mathrm{~A}$ combination of bicuspid aortic valve, coarctation of the aorta, aortic aneurysm and aortic dissection; ${ }^{+}$Abdominal aortic aneurysm and thoracic aortic aneurysm. In several researches, the data of subtypes of aortic aneurysm was not fully provided; ${ }^{\ddagger} P$-value for analysis of variance between four aortic diseases of the number of IAs per person.

aortopathy (BAV, CoA, aortic aneurysm, and aortic dissection) suffered from IAs, which is approximately four times that of the general population (3.2\%). ${ }^{1}$ The prevalence of IA for aortic dissection group is probably twice the prevalence in patients with aortopathy. Gender (female) and smoking are two risk factors related to an increased risk of IAs. Furthermore, a sitespecific relationship between different aortic disease and the anatomical location of IAs is mapped.

\section{Potential mechanism}

There are several mechanisms for the coexistence of IAs and aortic diseases. The abnormality of cells derived from the neural crest could explain the association between IA and aortopa- thy. ${ }^{10}$ The neural crest cells are a group of transient and multipotent cells in early embryogenesis which is induced to migrate and give rise to several cell lineages. The tunica media of the aortic arch and its branches, including the cervicocephalic arteries are composed of cells derived from neural crest, and the abnormal development of the neural crest cells may result in vascular fragility, and this could cause simultaneous IAs and aortic diseases. ${ }^{10,22-25}$

Furthermore, the genetic relation of IA and aortopathy has been examined in researches. ${ }^{26-34}$ Multiple types of gene mutation play a critical role in this relationship: single nucleotide polymorphisms, ${ }_{1}^{27,35}$ frameshift mutations in exons, ${ }^{28}$ and translocations of chromosome ${ }_{1}^{29}$ which demonstrates that the gene- 
related association between IA and aortopathy is rather complicated. In particular, patients with connective tissue diseases such as Loeys-Dietz syndrome, Marfan syndrome, Ehlers-Danlos syndrome, and neurofibromatosis type 1 are thought to be at a higher risk for IAs and aortopathy. ${ }^{36,37}$ The widely accepted causal explanation of this relationship is that the genetic mutations in such connective tissue disorders affect the collagen and proteoglycans in extracellular matrix, thus leading to the weakening of the vascular wall. ${ }^{37}$

Acquired risk factors could also increase the risk of IA and aortic disorders. The dominant environmental risk factors for aneurysms include age, gender, smoking, alcohol, and hypertension. ${ }^{35,38}$ Hypertension is a known risk factor for the development of IA ${ }_{1}^{35}$ aortic aneurysm ${ }_{1}^{39}$ and aortic dissection. ${ }^{40}$ Blood flow or blood pressure is an important modulator of arterial growth. Wall shear stress is strictly regulated in bodies, with the normal artery enlarging in response to increases in blood flow to maintain normal shear stress. ${ }^{35}$ However, high blood pressure in patients with hypertension could significantly affect the shear stress, which could lead to an abnormal expansion of blood vessels.

\section{Prevalence of IA}

The pooled prevalence of IA among patients with distinct aortic disease in this research is similar to that of previous observational study. ${ }^{3,5-13}$ The estimated prevalence of IA for patients with aortic dissection (23\%; $95 \% \mathrm{Cl}, 12 \%$ to $34 \%$ ) is much higher compared with that in groups suffered from other aortic diseases. Study quality is moderate and heterogeneity source could be identified through subgroup analysis. The heterogeneity within or between subgroups is limited, which indicates that the relationship between IA and aortopathy is robust regardless of the type of aortopathy. The overall estimated prevalence of IA is around 12\% in patients with aortopathy, which is quadrupled compared to that of the general population, and the prevalence of IA in patients suffered from BAV, CoA, aortic aneurysm, aortic dissection is $8 \%, 10 \%, 12 \%$, and $23 \%$ respectively. BAV and CoA are congenital diseases, and aortic aneurysm or dissection could be induced by acquired factors, and the prevalence of aortic aneurysm or dissection is higher, which indicates that hemodynamic or environmental factors play an essential role in the pathogenesis of IA and aortopathy. The result emphasizes that IA screenings could be conducted among patients with aortic diseases, especially patients with a dissection of the aorta. Importantly, the cost for population screening for IA is considerable, and a cost-effective study in this field is required.

In the surgical intervention of aortopathy, patients could suddenly die for a nubilous reason, and this might be associated with IA or other cerebrovascular accidents. Our findings should be relevant for neurologists, cardiac surgeons, patients with aortopathy and policymakers.

\section{Risk factors}

In this research, the effect of gender, age, smoking, hypertension, diabetes, hyperlipidemia, and the overlapping with two aortic diseases on the prevalence of IA in aortopathy sufferers are quantitatively analyzed (Figure 3 ). Gender (female) and smoking could be risk factors for IAs among patients with aortic diseases. However, study numbers and sample sizes in pooled analyses for risk factors are small (Figure 3), and it could somewhat reduce the statistical power of analyses. Thus, large observational studies are needed to identify precise risk factors for IAs among patients with aortopathy. Priority should be given to patients with special risk factors in population screening for IAs.

\section{Site-specific distribution of IA}

A site-specific distribution pattern of IA between groups with different aortopathy is observed in the review. The anatomical distribution of IAs differed significantly in patients with distinct aortic disease. Despite a heterogeneous frequency of ICA$I A$ and Post-IA among different groups, the frequency of AntIA is confoundedly stable among patients suffered from distinct aortopathy. Additionally, the frequency of Ant-IA is the largest in three predefined IA groups. Genetic risk factors are suggested to have a larger role of IA at the middle cerebral artery (contained in Ant-IA) than at other sites of the cerebrovascular system. ${ }^{41}$ Consistently, genetic factors are critical in the development of BAV, CoA, aortic aneurysm, and aortic dissection. ${ }^{42-45}$ The result suggests a shared pathological mechanism between IA and aortopathy. ${ }^{8}$ The stable distribution of Ant-IA might suggest that the connection between aortopathy and IA is strongly associated with the human gene. Distinct allocation of IAs in ICA-IA and Post-IA could accompany with exclusive pathological features of aortic diseases, and this issue should be further explored. We expect subtypes of aortic aneurysm, and we analyze the site of IA in thoracic aortic aneurysm and abdominal aortic aneurysm separately. However, the margin between two groups was not statistically significant, which is inconsistent with a previous study. ${ }^{8}$ Shin et al. ${ }^{8}$ deliver a differing distribution patterns of IA among subgroups of aortic aneurysm (ascending aneurysm, descending thoracic-suprarenal aneurysms, and infrarenal aneurysm) with 71 participants. We consider the study population is too small to confirm the relationship, and different classifications could somewhat af- 
fect the result. It is known that genes in the pathogenesis of IA and thoracic aortic aneurysm are closely related, and the pathogenesis of abdominal aortic aneurysm is tended to be more atherosclerotic, but both thoracic aortic aneurysm and abdominal aortic aneurysm affected by hemodynamic and environmental factors. This could explain why the site distribution of IA in two groups is not totally different. Since the sample size of the site-specific analysis is still small, future work is needed on this issue to further test the relationship.

\section{Prevalence of aortopathy}

The qualitative part of this review analyzes the presence of aortic disease in patients with IA. Reports from included studies ${ }^{18-20}$ lack credible controls that could provide a reliable overall incidence/prevalence of aortic disease in the general population. Unlike IAs, aortic diseases get considerable symptoms and multiple diagnostic methods, and usually it is easier to diagnose aortic disease than IA. However, as increasing small IAs are found incidentally on neuroimaging, a substantial group of patients with IAs may benefit from screening for aortic vascular pathology.

\section{Strengths and limitations}

To the best of our knowledge, this study is the first comprehensive systematic review of the relationship between IA and aortopathy. We focus on the impact of cardiovascular risk factors on the overall prevalence, and the result indicates that the presence of aortopathy could be a predictor of IA. The specific distribution pattern of IAs in distinct aortic disease is also mapped in this research. The current review has several limitations. The methodological differences (e.g., diagnostic methods for events) in the original studies lead to inevitable heterogeneity. Although we include 10 studies to quantify the prevalence and the effect of risk factors on the prevalence, the small sample size could somewhat reduce the statistical power and increase the error of statistical analyses. Other risk factors (e.g., alcohol, history of stroke) are also reported, but we are incapable of evaluating these factors due to the limited studies. Complete records of the number and anatomical location for IA in single participants are not fully provided, we are unable to assess the association between different aortopathy and the number of IAs in individuals.

\section{Conclusions}

Overall, the present systematic review indicates that the prevalence of IA in patients suffered from aortic disease is quadrupled compared to that in the general population. Gender (female) and smoking are associated with an increased risk of IA among patients with aortic disease. A heterogeneous distribution pattern of IAs exists among patients with different aortic disease. Since the definite mechanism how aortopathy interact with IA is still unclear, genetic work and biological experiments on this issue are needed. A worldwide epidemiological study, however, with effective controls and large sample size, is also required in this field to produce a credible and conclusive result.

\section{Supplementary materials}

Supplementary materials related to this article can be found online at https://doi.org/10.5853/jos.2019.01312.

\section{Disclosure}

The authors have no financial conflicts of interest.

\section{Acknowledgments}

This review was supported by the National Natural Science Foundation of China (NSFC,71603091).

\section{References}

1. Vlak MH, Algra A, Brandenburg R, Rinkel GJ. Prevalence of unruptured intracranial aneurysms, with emphasis on sex, age, comorbidity, country, and time period: a systematic review and meta-analysis. Lancet Neurol 2011;10:626-636.

2. Algra $A M$, Lindgren $A$, Vergouwen $M D I$, Greving JP, van der Schaaf IC, van Doormaal TPC, et al. Procedural clinical complications, case-fatality risks, and risk factors in endovascular and neurosurgical treatment of unruptured intracranial aneurysms: a systematic review and meta-analysis. JAMA Neurol 2019;76:282-293.

3. Jung WS, Kim JH, Ahn SJ, Song SW, Kim BM, Seo KD, et al. Prevalence of intracranial aneurysms in patients with aortic dissection. AJNR Am J Neuroradiol 2017;38:2089-2093.

4. Thompson BG, Brown RD Jr, Amin-Hanjani S, Broderick JP, Cockroft KM, Connolly ES Jr, et al. Guidelines for the management of patients with unruptured intracranial aneurysms: a guideline for healthcare professionals from the American Heart Association/American Stroke Association. Stroke 2015;46: 2368-2400.

5. Kuzmik GA, Feldman $M$, Tranquilli $M$, Rizzo JA, Johnson $M$, Elefteriades JA. Concurrent intracranial and thoracic aortic aneurysms. Am J Cardiol 2010;105:417-420.

6. Lee D, Ahn SJ, Cho ES, Kim YB, Song SW, Jung WS, et al. 
High prevalence of intracranial aneurysms in patients with aortic dissection or aneurysm: feasibility of extended aorta CT angiography with involvement of intracranial arteries. $J$ Neurointerv Surg 2017;9:1017-1021.

7. Rouchaud A, Brandt MD, Rydberg AM, Kadirvel R, Flemming $\mathrm{K}$, Kallmes DF, et al. Prevalence of intracranial aneurysms in patients with aortic aneurysms. AJNR Am J Neuroradiol 2016;37:1664-1668.

8. Shin YW, Jung KH, Moon J, Lee ST, Lee SK, Chu K, et al. Sitespecific relationship between intracranial aneurysm and aortic aneurysm. Stroke 2015;46:1993-1996.

9. Cook SC, Hickey J, Maul TM, Zumberge N, Krieger EV, Valente $\mathrm{AM}$, et al. Assessment of the cerebral circulation in adults with coarctation of the aorta. Congenit Heart Dis 2013;8:289-295.

10. Schievink WI, Raissi SS, Maya MM, Velebir A. Screening for intracranial aneurysms in patients with bicuspid aortic valve. Neurology 2010;74:1430-1433.

11. Connolly HM, Huston J 3rd, Brown RD Jr, Warnes CA, Ammash NM, Tajik AJ. Intracranial aneurysms in patients with coarctation of the aorta: a prospective magnetic resonance angiographic study of 100 patients. Mayo Clin Proc 2003;78:14911499.

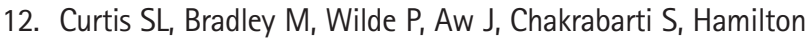
$M$, et al. Results of screening for intracranial aneurysms in patients with coarctation of the aorta. AJNR Am J Neuroradiol 2012;33:1182-1186.

13. Egbe AC, Padang R, Brown RD, Khan AR, Luis SA, Huston J 3rd, et al. Prevalence and predictors of intracranial aneurysms in patients with bicuspid aortic valve. Heart 2017;103:1508-1514.

14. Moher D, Liberati A, Tetzlaff J, Altman DG; PRISMA Group. Preferred reporting items for systematic reviews and meta-analyses: the PRISMA statement. PLoS Med 2009;6:e1000097.

15. Fralick M, Sy E, Hassan A, Burke MJ, Mostofsky E, Karsies T. Association of concussion with the risk of suicide: a systematic review and meta-analysis. JAMA Neurol 2019;76:144151.

16. Søvik $S$, Isachsen MS, Nordhuus KM, Tveiten CK, Eken T,

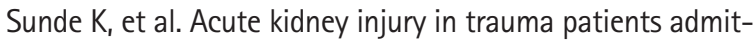
ted to the ICU: a systematic review and meta-analysis. Intensive Care Med 2019;45:407-419.

17. Donti A, Spinardi L, Brighenti M, Faccioli L, Leoni C, Fabi M, et al. Frequency of intracranial aneurysms determined by magnetic resonance angiography in children (mean age 16) having operative or endovascular treatment of coarctation of the aorta (mean age 3). Am J Cardiol 2015;116:630-633.

18. Wang JC, Chien WC, Chung CH, Lin CY, Chen YH, Liao MT, et al. Association between surgical repair of aortic aneurysms and the diagnosis of intracranial aneurysms. J Vasc Surg
2020;71:481-489.

19. Goyal MS, Gottumukkala R, Bhalla S, Kates A, Zipfel GJ, Derdeyn CP. Bicuspid aortic valves and thoracic aortic aneurysms in patients with intracranial aneurysms. Neurology 2015;84:46-49.

20. Miyazawa N, Akiyama I, Yamagata Z. Risk factors for the association of intracranial and aortic aneurysms. Acta Neurochir (Wien) 2007;149:221-229.

21. Laukka D, Pan E, Fordell T, Alpay K, Rahi M, Hirvonen J, et al. Prevalence of thoracic aortic aneurysms and dilatations in patients with intracranial aneurysms. J Vasc Surg 2019;70:18011808.

22. Kappetein $A P$, Gittenberger-de Groot $A C$, Zwinderman $A H$, Rohmer J, Poelmann RE, Huysmans HA. The neural crest as a possible pathogenetic factor in coarctation of the aorta and bicuspid aortic valve. J Thorac Cardiovasc Surg 1991;102:830836.

23. Kirby ML, Gale TF, Stewart DE. Neural crest cells contribute to normal aorticopulmonary septation. Science 1983;220:10591061.

24. Le Douarin NM. The avian embryo as a model to study the development of the neural crest: a long and still ongoing story. Mech Dev 2004;121:1089-1102.

25. Rosenquist $T H$, Beall $A C$, Módis L, Fishman R. Impaired elastic matrix development in the great arteries after ablation of the cardiac neural crest. Anat Rec 1990;226:347-359.

26. Baas AF, Medic J, van't Slot $R$, de Vries JP, van Sambeek MR, Verhoeven $E L$, et al. The intracranial aneurysm susceptibility genes HSPG2 and CSPG2 are not associated with abdominal aortic aneurysm. Angiology 2010;61:238-242.

27. Helgadottir A, Thorleifsson G, Magnusson KP, Grétarsdottir S, Steinthorsdottir $V$, Manolescu $A$, et al. The same sequence variant on 9p21 associates with myocardial infarction, abdominal aortic aneurysm and intracranial aneurysm. Nat Genet 2008;40:217-224.

28. Jelsig AM, Urban Z, Hucthagowder V, Nissen H, Ousager LB. Novel ELN mutation in a family with supravalvular aortic stenosis and intracranial aneurysm. Eur J Med Genet 2017;60:110113.

29. Luukkonen TM, Pöyhönen $M$, Palotie $A$, Ellonen $P$, Lagström $\mathrm{S}$, Lee $\mathrm{JH}$, et al. A balanced translocation truncates Neurotri$\min$ in a family with intracranial and thoracic aortic aneurysm. J Med Genet 2012;49:621-629.

30. Regalado E, Medrek S, Tran-Fadulu V, Guo DC, Pannu H, Golabbakhsh $\mathrm{H}$, et al. Autosomal dominant inheritance of a predisposition to thoracic aortic aneurysms and dissections and intracranial saccular aneurysms. Am J Med Genet $A$ 2011;155A:2125-2130. 
31. Regalado ES, Guo DC, Villamizar C, Avidan N, Gilchrist D, McGillivray $B$, et al. Exome sequencing identifies SMAD3 mutations as a cause of familial thoracic aortic aneurysm and dissection with intracranial and other arterial aneurysms. Circ Res 2011;109:680-686.

32. Ruigrok YM, Elias R, Wijmenga $C$, Rinkel GJ. A comparison of genetic chromosomal loci for intracranial, thoracic aortic, and abdominal aortic aneurysms in search of common genetic risk factors. Cardiovasc Pathol 2008;17:40-47.

33. van 't Hof FN, Ruigrok YM, Lee CH, Ripke S, Anderson G, de Andrade $\mathrm{M}_{1}$ et al. Shared genetic risk factors of intracranial, abdominal, and thoracic aneurysms. J Am Heart Assoc 2016;5:e002603.

34. Worrall BB, Foroud T, Brown RD Jr, Connolly ES, Hornung RW, Huston J 3rd, et al. Genome screen to detect linkage to common susceptibility genes for intracranial and aortic aneurysms. Stroke 2009;40:71-76.

35. Norman PE, Powell JT. Site specificity of aneurysmal disease. Circulation 2010;121:560-568.

36. Loeys-Dietz syndrome. In: Chen H. Atlas of Genetic Diagnosis and Counseling. New York, NY: Springer US, 2012;12951300.

37. Kim ST, Brinjikji W, Lanzino G, Kallmes DF. Neurovascular manifestations of connective-tissue diseases: a review. Interv Neuroradiol 2016;22:624-637.

38. Jung KH. New pathophysiological considerations on cerebral aneurysms. Neurointervention 2018;13:73-83.

39. Kobeissi $E_{1}$ Hibino M, Pan H, Aune D. Blood pressure, hyper- tension and the risk of abdominal aortic aneurysms: a systematic review and meta-analysis of cohort studies. Eur J Epidemiol 2019;34:547-555.

40. Erbel R, Aboyans V, Boileau C, Bossone E, Bartolomeo RD,

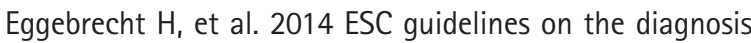
and treatment of aortic diseases: document covering acute and chronic aortic diseases of the thoracic and abdominal aorta of the adult. The Task Force for the Diagnosis and Treatment of Aortic Diseases of the European Society of Cardiology (ESC). Eur Heart J 2014;35:2873-2926.

41. van 't Hof FN, Kurki Ml, Kleinloog $\mathrm{R}$, de Bakker Pl, von und zu Fraunberg $M$, Jääskeläinen $\mathrm{J}_{\text {, }}$ et al. Genetic risk load according to the site of intracranial aneurysms. Neurology 2014;83: 34-39.

42. Gould RA, Aziz H, Woods CE, Seman-Senderos MA, Sparks E, Preuss $C_{\text {, }}$ et al. ROBO4 variants predispose individuals to bicuspid aortic valve and thoracic aortic aneurysm. Nat Genet 2019;51:42-50

43. Bjornsson $T$, Thorolfsdottir RB, Sveinbjornsson $G$, Sulem $P$, Norddahl GL, Helgadottir $A$, et al. A rare missense mutation in MYH6 associates with non-syndromic coarctation of the aorta. Eur Heart J 2018;39:3243-3249.

44. Pinard A, Jones GT, Milewicz DM. Genetics of thoracic and abdominal aortic diseases. Circ Res 2019;124:588-606.

45. Renard M, Francis $C$, Ghosh $R$, Scott AF, Witmer PD, Adès LC, et al. Clinical validity of genes for heritable thoracic aortic aneurysm and dissection. J Am Coll Cardiol 2018;72:605615. 


\section{Supplementary Material}

\section{Search strategy}

(1) Pubmed

(aorta OR aortic dissection OR aortic aneurysm OR aortic dilatation $\mathrm{OR}$ coarctation of the aorta $\mathrm{OR}$ aortic coarctation $\mathrm{OR}$ bicuspid aortic valve OR aortopathy) AND (intracranial aneurysm OR brain aneurysm OR cerebral aneurysm)

\section{(2) Scopus}

(TITLE-ABS-KEY (aorta) OR TITLE-ABS-KEY (aortic AND dissection) OR TITLE-ABS-KEY (aortic AND aneurysm) OR TITLEABS-KEY (aortic AND dilatation) OR TITLE-ABS-KEY (coarctation AND of AND the AND aorta) OR TITLE-ABS-KEY (aortic AND coarctation) OR TITLE-ABS-KEY (bicuspid AND aortic AND valve) OR TITLE-ABS-KEY (aortopathy) AND TITLEABS-KEY (intracranial AND aneurysm)

\section{PRISMA 2009 checklist}

\begin{tabular}{|c|c|c|c|}
\hline Section/topic & \# & Checklist item & $\begin{array}{l}\text { Reported on } \\
\text { page \# }\end{array}$ \\
\hline \multicolumn{4}{|l|}{ Title } \\
\hline Title & 1 & Identify the report as a systematic review, meta-analysis, or both. & 1 \\
\hline \multicolumn{4}{|l|}{ Abstract } \\
\hline Structured summary & 2 & $\begin{array}{l}\text { Provide a structured summary including, as applicable: background; objectives; data sources; study eligibility } \\
\text { criteria, participants, and interventions; study appraisal and synthesis methods; results; limitations; conclu- } \\
\text { sions and implications of key findings; systematic review registration number. }\end{array}$ & 2 \\
\hline \multicolumn{4}{|l|}{ Introduction } \\
\hline Rationale & 3 & Describe the rationale for the review in the context of what is already known. & 3 \\
\hline Objectives & 4 & $\begin{array}{l}\text { Provide an explicit statement of questions being addressed with reference to participants, interventions, com- } \\
\text { parisons, outcomes, and study design (PICOS). }\end{array}$ & $4-5$ \\
\hline \multicolumn{4}{|l|}{ Methods } \\
\hline $\begin{array}{l}\text { Protocol and registra- } \\
\text { tion }\end{array}$ & 5 & $\begin{array}{l}\text { Indicate if a review protocol exists, if and where it can be accessed (e.g., Web address), and, if available, provide } \\
\text { registration information including registration number. }\end{array}$ & NR \\
\hline Eligibility criteria & 6 & $\begin{array}{l}\text { Specify study characteristics (e.g., PICOS, length of follow-up) and report characteristics (e.g., years considered, } \\
\text { language, publication status) used as criteria for eligibility, giving rationale. }\end{array}$ & 4 \\
\hline Information sources & 7 & $\begin{array}{l}\text { Describe all information sources (e.g., databases with dates of coverage, contact with study authors to identify } \\
\text { additional studies) in the search and date last searched. }\end{array}$ & $4-5$ \\
\hline Search & 8 & $\begin{array}{l}\text { Present full electronic search strategy for at least one database, including any limits used, such that it could be } \\
\text { repeated. }\end{array}$ & 4 \\
\hline Study selection & 9 & $\begin{array}{l}\text { State the process for selecting studies (i.e., screening, eligibility, included in systematic review, and, if applicable, } \\
\text { included in the meta-analysis). }\end{array}$ & $4-5$ \\
\hline Data collection process & 10 & $\begin{array}{l}\text { Describe method of data extraction from reports (e.g., piloted forms, independently, in duplicate) and any pro- } \\
\text { cesses for obtaining and confirming data from investigators. }\end{array}$ & $4-5$ \\
\hline Data items & 11 & $\begin{array}{l}\text { List and define all variables for which data were sought (e.g., PICOS, funding sources) and any assumptions and } \\
\text { simplifications made. }\end{array}$ & $4-5$ \\
\hline $\begin{array}{l}\text { Risk of bias in individu- } \\
\text { al studies }\end{array}$ & 12 & $\begin{array}{l}\text { Describe methods used for assessing risk of bias of individual studies (including specification of whether this } \\
\text { was done at the study or outcome level), and how this information is to be used in any data synthesis. }\end{array}$ & 5 \\
\hline Summary measures & 13 & State the principal summary measures (e.g., risk ratio, difference in means). & $5-6$ \\
\hline Synthesis of results & 14 & $\begin{array}{l}\text { Describe the methods of handling data and combining results of studies, if done, including measures of consis- } \\
\text { tency }\left(\text { e.g., } I^{2}\right) \text { for each meta-analysis. }\end{array}$ & 6 \\
\hline $\begin{array}{l}\text { Risk of bias across } \\
\text { studies }\end{array}$ & 15 & $\begin{array}{l}\text { Specify any assessment of risk of bias that may affect the cumulative evidence (e.g., publication bias, selective } \\
\text { reporting within studies). }\end{array}$ & 5 \\
\hline Additional analyses & 16 & $\begin{array}{l}\text { Describe methods of additional analyses (e.g., sensitivity or subgroup analyses, meta-regression), if done, indi- } \\
\text { cating which were pre-specified. }\end{array}$ & 6 \\
\hline
\end{tabular}




\begin{tabular}{|c|c|c|c|}
\hline Section/topic & $\#$ & Checklist item & $\begin{array}{l}\text { Reported on } \\
\text { page \# }\end{array}$ \\
\hline \multicolumn{4}{|l|}{ Results } \\
\hline Study selection & 17 & $\begin{array}{l}\text { Give numbers of studies screened, assessed for eligibility, and included in the review, with reasons for exclusions } \\
\text { at each stage, ideally with a flow diagram. }\end{array}$ & 7, Figure 1 \\
\hline Study characteristics & 18 & $\begin{array}{l}\text { For each study, present characteristics for which data were extracted (e.g., study size, PICOS, follow-up period) } \\
\text { and provide the citations. }\end{array}$ & 7, Table 1 \\
\hline $\begin{array}{l}\text { Risk of bias within } \\
\text { studies }\end{array}$ & 19 & Present data on risk of bias of each study and, if available, any outcome level assessment (see item 12). & $7-8$ \\
\hline $\begin{array}{l}\text { Results of individual } \\
\text { studies }\end{array}$ & 20 & $\begin{array}{l}\text { For all outcomes considered (benefits or harms), present, for each study: (a) simple summary data for each in- } \\
\text { tervention group (b) effect estimates and confidence intervals, ideally with a forest plot. }\end{array}$ & $\begin{array}{c}\text { 8-9, } \\
\text { Figures 2-4 }\end{array}$ \\
\hline Synthesis of results & 21 & Present results of each meta-analysis done, including confidence intervals and measures of consistency. & $8-9$ \\
\hline $\begin{array}{l}\text { Risk of bias across } \\
\text { studies }\end{array}$ & 22 & Present results of any assessment of risk of bias across studies (see Item 15). & $\begin{array}{c}9, \\
\text { Figures 2-4 }\end{array}$ \\
\hline Additional analysis & 23 & Give results of additional analyses, if done (e.g., sensitivity or subgroup analyses, meta-regression [see Item 16]). & $\begin{array}{l}\text { 8-9, } \\
\text { Figures 2-4 }\end{array}$ \\
\hline \multicolumn{4}{|l|}{ Discussion } \\
\hline Summary of evidence & 24 & $\begin{array}{l}\text { Summarize the main findings including the strength of evidence for each main outcome; consider their rele- } \\
\text { vance to key groups (e.g., healthcare providers, users, and policy makers). }\end{array}$ & $9-10$ \\
\hline Limitations & 25 & $\begin{array}{l}\text { Discuss limitations at study and outcome level (e.g., risk of bias), and at review-level (e.g., incomplete retrieval } \\
\text { of identified research, reporting bias). }\end{array}$ & 12 \\
\hline Conclusions & 26 & $\begin{array}{l}\text { Provide a general interpretation of the results in the context of other evidence, and implications for future re- } \\
\text { search. }\end{array}$ & 12 \\
\hline \multicolumn{4}{|l|}{ Funding } \\
\hline Funding & 27 & $\begin{array}{l}\text { Describe sources of funding for the systematic review and other support (e.g., supply of data); role of funders for } \\
\text { the systematic review. }\end{array}$ & 13 \\
\hline
\end{tabular}

Adapted from Moher et al. ${ }^{14}$ For more information, visit: www.prisma-statement.org.

PRISMA, Preferred Reporting Items for Systematic Reviews and Meta-Analyses; NR, not reported. 
Supplementary Table 1. Modified Newcastle-Ottawa scale for assessing the quality of included studies

\begin{tabular}{|c|c|c|c|c|c|c|c|c|c|}
\hline \multirow[b]{2}{*}{ Study } & \multirow[b]{2}{*}{ Study design } & \multicolumn{4}{|c|}{ Selection $(\max =4)$} & \multirow{2}{*}{$\begin{array}{c}\begin{array}{c}\text { Comparability } \\
\text { (max=2) }\end{array} \\
\begin{array}{c}\text { Based on design or } \\
\text { analysis }\end{array}\end{array}$} & \multicolumn{2}{|c|}{ Outcome (max=3) } & \multirow{2}{*}{$\begin{array}{c}\text { Total } \\
\text { score } \\
(\mathrm{max}=9)\end{array}$} \\
\hline & & $\begin{array}{l}\text { Representa- } \\
\text { tive } \\
\text { sample }\end{array}$ & $\begin{array}{l}\text { Sample } \\
\text { size ade- } \\
\text { quate }\end{array}$ & $\begin{array}{l}\text { Non-re- } \\
\text { spondents }\end{array}$ & $\begin{array}{c}\text { Ascertain- } \\
\text { ment } \\
\text { of exposure }\end{array}$ & & $\begin{array}{l}\text { Assessment } \\
\text { of outcome }\end{array}$ & $\begin{array}{c}\text { Statistical } \\
\text { test }\end{array}$ & \\
\hline Miyazawa et al. $(2007)^{20}$ & Cross-sectional & (:) & (:) & - & (:) & (:) (:) & (:) & (:) & 7 \\
\hline Goyal et al. $(2015)^{19}$ & Cross-sectional & (;) & (;) & - & (;) & (;) & (;) & (;) & 6 \\
\hline Laukka et al. (2019) ${ }^{21}$ & Cross-sectional & (;) & (;) & & $\odot$ & $+;$ & ;) & (:) & 7 \\
\hline Connolly et al. (2003) ${ }^{11}$ & Cross-sectional & (;) & (:) & (:) & (;) & (;) & (;) & (:) & 7 \\
\hline Cook et al. $(2013)^{9}$ & Cross-sectional & (:) & (:) & - & ;) & (:) & (:) & (:) & 6 \\
\hline Curtis et al. (2012) ${ }^{12}$ & Cross-sectional & (:) & (:) & - & (:) & (:) (:) & (:) & (:) & 7 \\
\hline Egbe et al. $(2017)^{13}$ & Cross-sectional & (:) & (:) & - & ;) & (:) $;$ & (:) & ;) & 7 \\
\hline Jung et al. $(2017)^{3}$ & Cross-sectional & (:) & (;) & - & (;) & (;) & (;) & ;) & 6 \\
\hline Kuzmik et al. (2010) ${ }^{5}$ & Cross-sectional & (:) & (:) & - & () & (;) & (;) & (:) & 6 \\
\hline Lee et al. $(2017)^{6}$ & Cross-sectional & (:) & (-) & - & (;) & (;) & (;) & (:) & 6 \\
\hline Rouchaud et al. (2016) & Cross-sectional & (:) & (:) & - & $\odot$ & $\odot$ & (:) & $\odot$ & 6 \\
\hline Schievink et al. $(2010)^{10}$ & Cross-sectional & (-) & (:) & - & (:) & (:) & (:) & (:) & 7 \\
\hline Shin et al. $(2015)^{8}$ & Cross-sectional & (;) & (;) & - & ;) & (:) & (-) & (:) & 6 \\
\hline
\end{tabular}




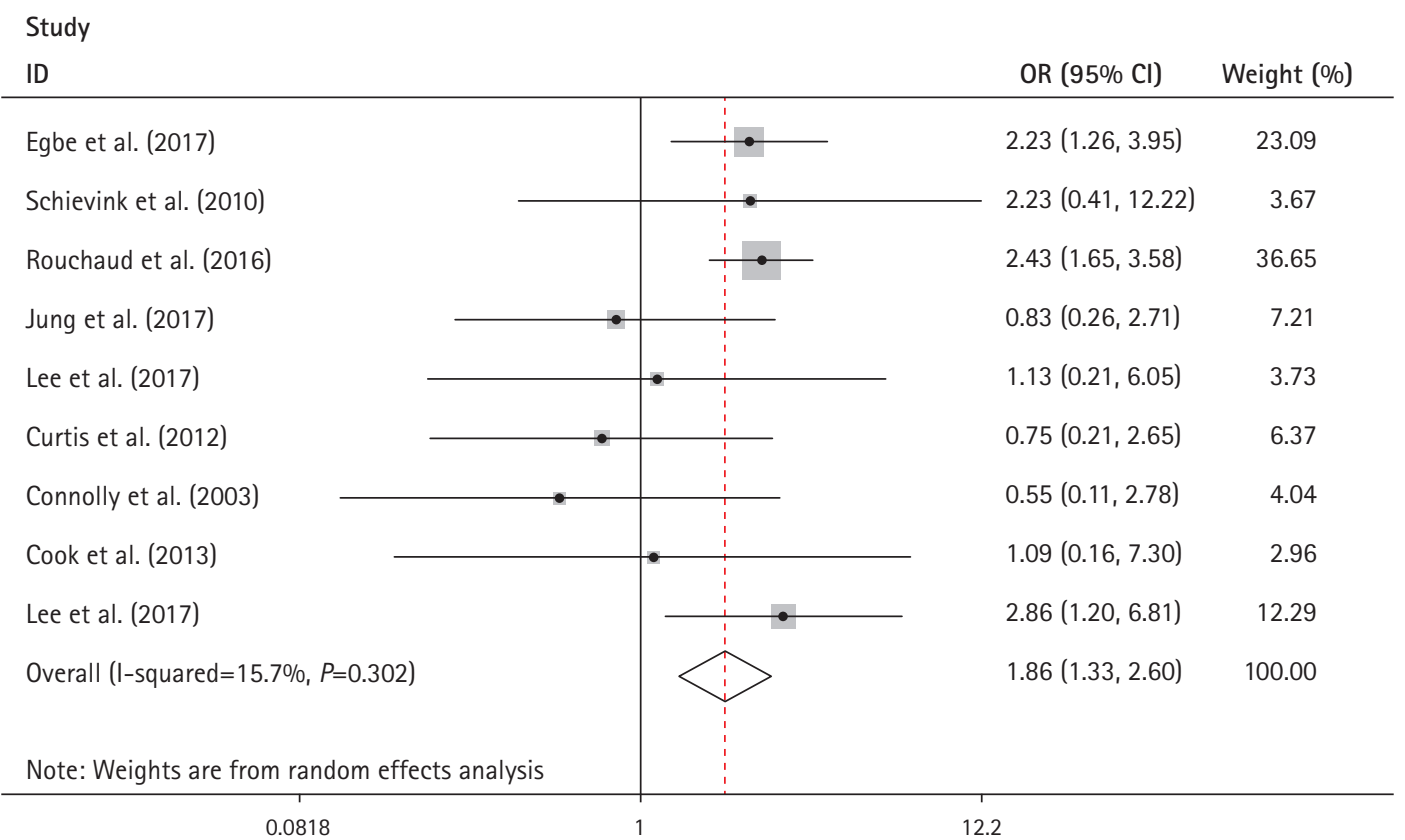

Supplementary Figure 1. Individual analysis of risk factors for the presence of intracranial aneurysms in patients with aortic diseases. Odds ratios (ORs) for female gender on the prevalence of intracranial aneurysm in patients suffered from aortic disease. $\mathrm{Cl}$, confidence interval.

\begin{tabular}{|c|c|c|}
\hline $\begin{array}{l}\text { Study } \\
\text { ID }\end{array}$ & OR $(95 \% \mathrm{Cl})$ & Weight (\%) \\
\hline Egbe et al. (2017) & $0.91(0.50,1.68)$ & 21.79 \\
\hline Schievink et al. (2010) & $0.75(0.13,4.46)$ & 2.57 \\
\hline Rouchaud et al. (2016) & $1.60(1.09,2.35)$ & 54.97 \\
\hline Jung et al. (2017) & $0.34(0.01,8.25)$ & 0.80 \\
\hline Lee et al. (2017) & $2.50(0.28,22.02)$ & 1.72 \\
\hline Curtis et al. (2012) & $2.59(0.70,9.57)$ & 4.77 \\
\hline Connolly et al. (2003) & $2.36(0.62,8.95)$ & 4.58 \\
\hline Lee et al. (2017) & $0.98(0.37,2.55)$ & 8.79 \\
\hline Overall (I-squared $=0.0 \%, P=0.564)$ & $1.38(1.04,1.83)$ & 100.00 \\
\hline Note: Weights are from random effects analysis & & \\
\hline
\end{tabular}

Supplementary Figure 2. Individual analysis of risk factors for the presence of intracranial aneurysms in patients with aortic diseases. Odds ratios (ORs) for smoking on the prevalence of intracranial aneurysm in patients suffered from aortic disease. $\mathrm{Cl}$, confidence interval. 


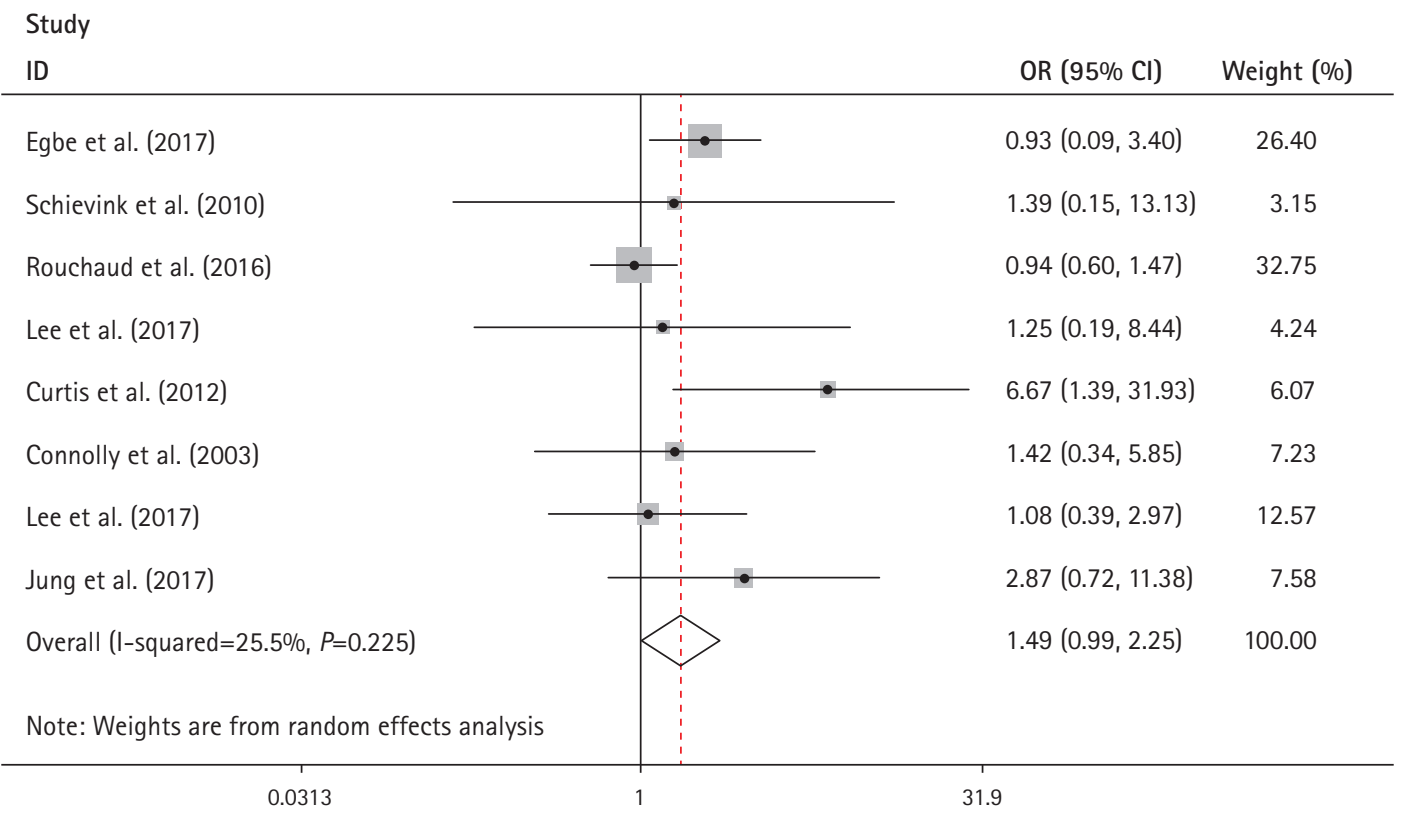

Supplementary Figure 3. Individual analysis of risk factors for the presence of intracranial aneurysms in patients with aortic diseases. Odds ratios (ORs) for hypertension on the prevalence of intracranial aneurysm in patients suffered from aortic disease. $\mathrm{Cl}$, confidence interval.

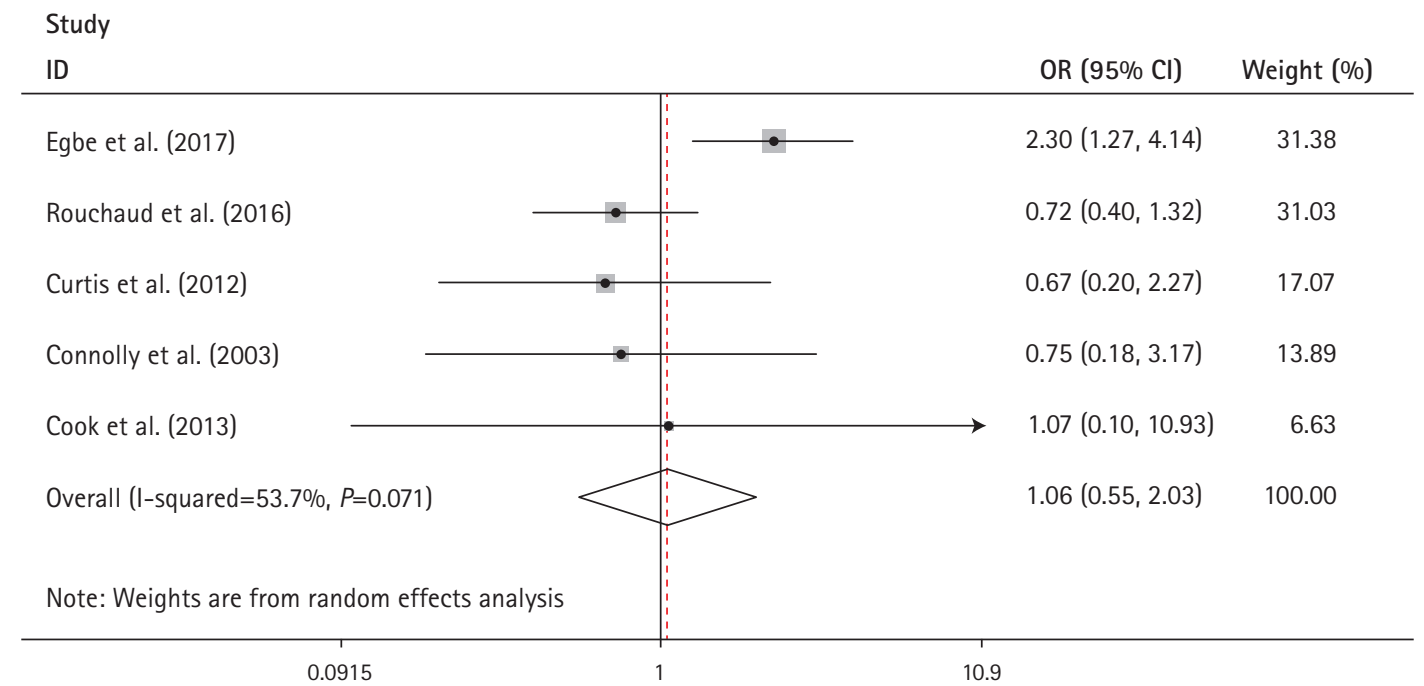

Supplementary Figure 4. Individual analysis of risk factors for the presence of intracranial aneurysms in patients with aortic diseases. Odds ratios (ORs) for the overlapping of two aortic diseases on the prevalence of intracranial aneurysm in patients suffered from aortic disease. $\mathrm{Cl}$, confidence interval. 
Study

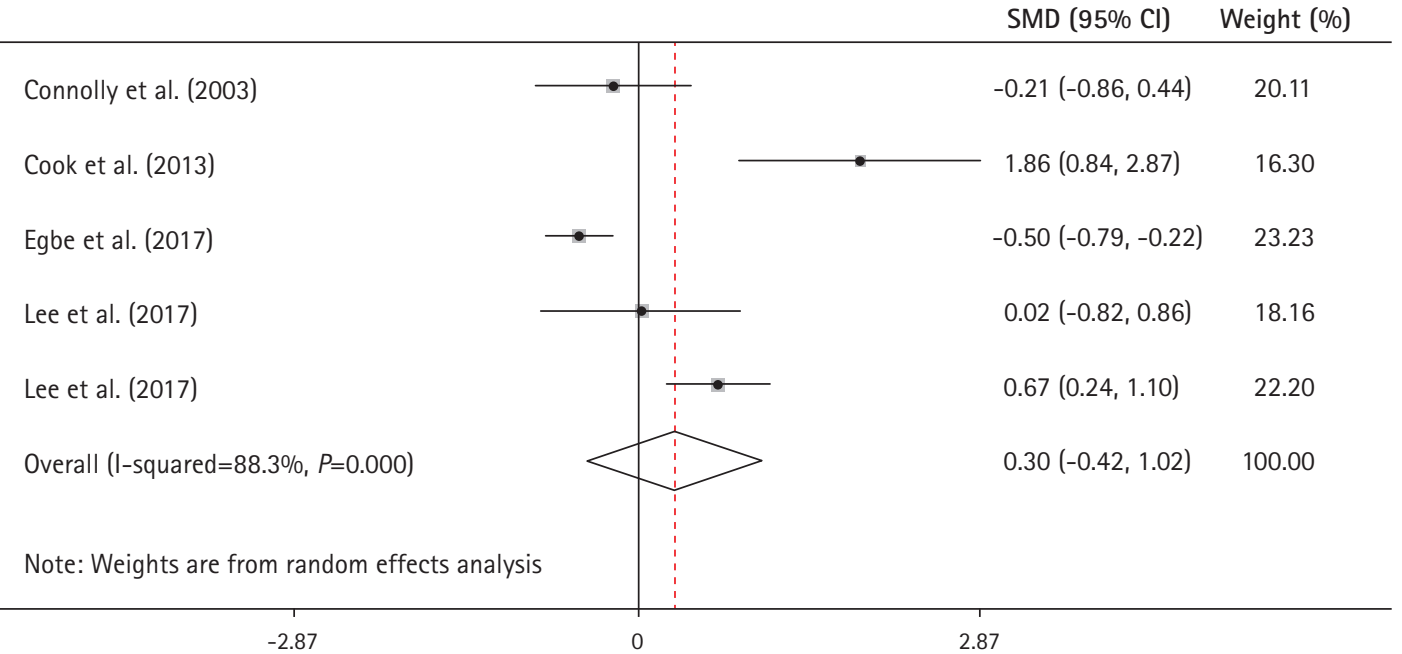

Supplementary Figure 5. Individual analysis of risk factors for the presence of intracranial aneurysms in patients with aortic diseases. Standard mean difference (SMD) for age on the prevalence of intracranial aneurysm in patients suffered from aortic disease. $\mathrm{Cl}$, confidence interval.

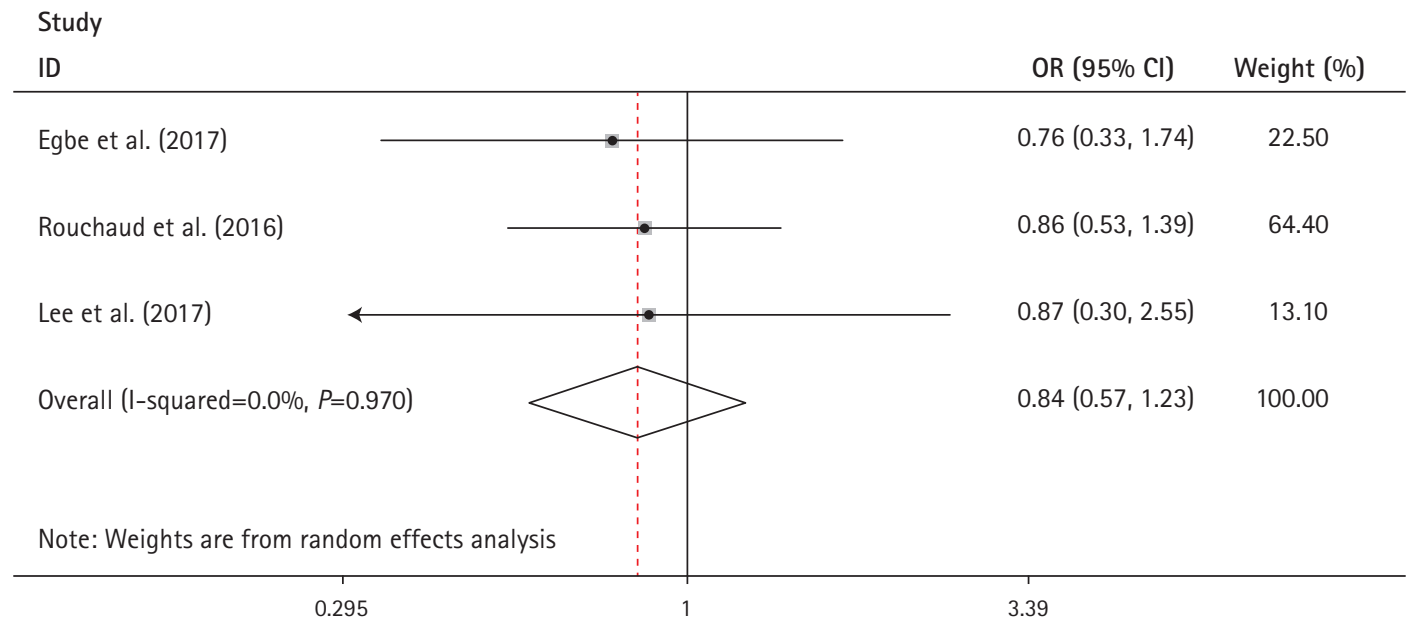

Supplementary Figure 6. Individual analysis of risk factors for the presence of intracranial aneurysms in patients with aortic diseases. Odds ratios (ORs) for diabetes on the prevalence of intracranial aneurysm in patients suffered from aortic disease. $\mathrm{Cl}$, confidence interval. 


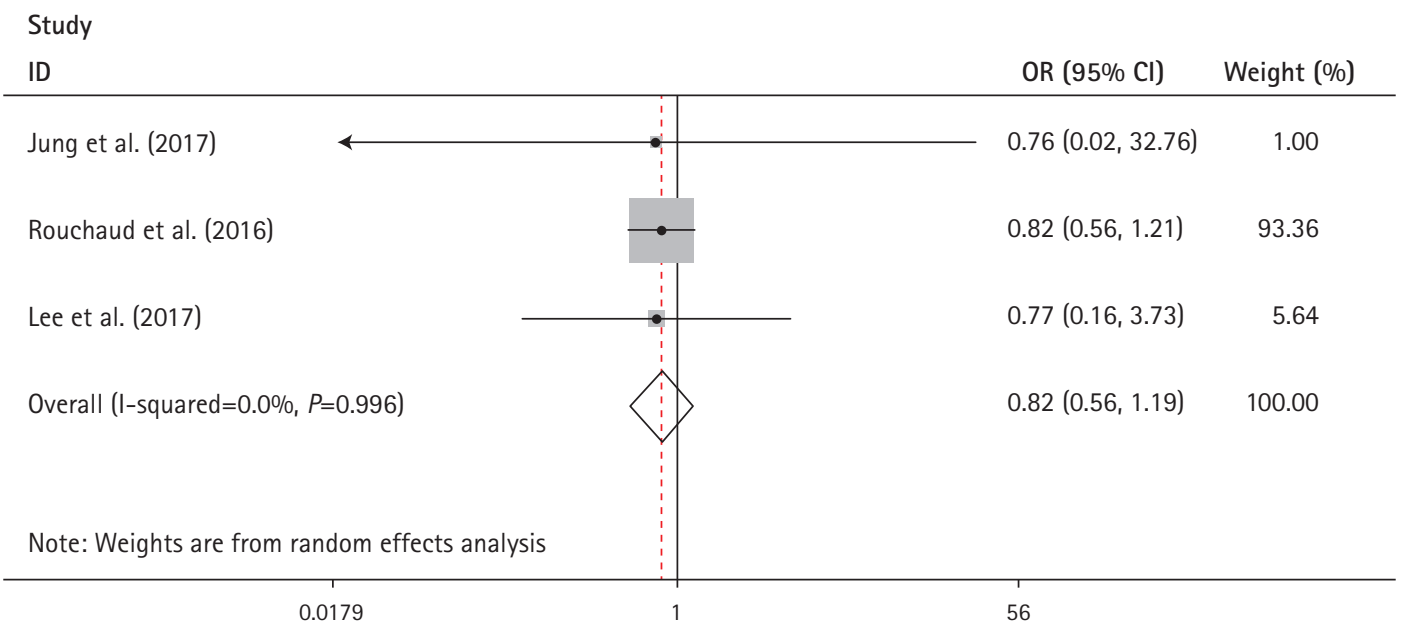

Supplementary Figure 7. Individual analysis of risk factors for the presence of intracranial aneurysms in patients with aortic diseases. Odds ratios (ORs) for hyperlipidemia on the prevalence of intracranial aneurysm in patients suffered from aortic disease. $\mathrm{Cl}$, confidence interval. 